\title{
The complete genome of Blastobotrys (Arxula) adeninivorans LS3 - a yeast of biotechnological interest
}

Gotthard Kunze ${ }^{1,25^{*}+}$, Claude Gaillardin ${ }^{2,3+}{ }^{4}$, Małgorzata Czernicka ${ }^{4}$, Pascal Durrens ${ }^{5}$, Tiphaine Martin ${ }^{5}$, Erik Böer ${ }^{1}$, Toni Gabaldón ${ }^{6,7}$, Jose A Cruz ${ }^{8}$, Emmanuel Talla9 ${ }^{9}$ Christian Marck ${ }^{10}$, André Goffeau ${ }^{11}$, Valérie Barbe ${ }^{12}$, Philippe Baret ${ }^{13}$, Keith Baronian ${ }^{14}$, Sebastian Beier ${ }^{1}$, Claudine Bleykasten ${ }^{15}$, Rüdiger Bode ${ }^{16}$, Serge Casaregola ${ }^{2,3}$, Laurence Despons $^{15}$, Cécile Fairhead ${ }^{17}$, Martin Giersberg ${ }^{1}$, Przemysław Piotr Gierski ${ }^{18}$, Urs Hähnel ${ }^{1}$, Anja Hartmann ${ }^{1}$, Dagmara Jankowska ${ }^{1}$, Claire Jubin ${ }^{12,19,20}$, Paul Jung ${ }^{15}$, Ingrid Lafontaine ${ }^{21}$, Véronique Leh-Louis ${ }^{15}$, Marc Lemaire ${ }^{22}$, Marina Marcet-Houben 6,7, Martin Mascher ${ }^{1}$, Guillaume Morel2,3, Guy-Franck Richard ${ }^{21}$, Jan Riechen ${ }^{1}$, Christine Sacerdot ${ }^{21,23}$, Anasua Sarkar ${ }^{5}$, Guilhem Savel ${ }^{5}$, Joseph Schacherer ${ }^{15}$, David J Sherman ${ }^{5}$, Nils Stein ${ }^{1}$, Marie-Laure Straub ${ }^{15}$, Agnès Thierry ${ }^{21}$, Anke Trautwein-Schult ${ }^{1}$, Benoit Vacherie ${ }^{12}$, Eric Westhof ${ }^{8}$, Sebastian Worch ${ }^{1}$, Bernard Dujon ${ }^{21}$, Jean-Luc Souciet ${ }^{15}$, Patrick Wincker ${ }^{12,19,20}$, Uwe Scholz ${ }^{1}$ and Cécile Neuvéglise 2,3,24* $^{*}$

\begin{abstract}
Background: The industrially important yeast Blastobotrys (Arxula) adeninivorans is an asexual hemiascomycete phylogenetically very distant from Saccharomyces cerevisiae. Its unusual metabolic flexibility allows it to use a wide range of carbon and nitrogen sources, while being thermotolerant, xerotolerant and osmotolerant.

Results: The sequencing of strain LS3 revealed that the nuclear genome of A. adeninivorans is $11.8 \mathrm{Mb}$ long and consists of four chromosomes with regional centromeres. Its closest sequenced relative is Yarrowia lipolytica, although mean conservation of orthologs is low. With 914 introns within 6116 genes, A. adeninivorans is one of the most intron-rich hemiascomycetes sequenced to date. Several large species-specific families appear to result from multiple rounds of segmental duplications of tandem gene arrays, a novel mechanism not yet described in yeasts. An analysis of the genome and its transcriptome revealed enzymes with biotechnological potential, such as two extracellular tannases (Atan1p and Atan2p) of the tannic-acid catabolic route, and a new pathway for the assimilation of n-butanol via butyric aldehyde and butyric acid.
\end{abstract}

Conclusions: The high-quality genome of this species that diverged early in Saccharomycotina will allow further fundamental studies on comparative genomics, evolution and phylogenetics. Protein components of different pathways for carbon and nitrogen source utilization were identified, which so far has remained unexplored in yeast, offering clues for further biotechnological developments. In the course of identifying alternative microorganisms for biotechnological interest, A. adeninivorans has already proved its strengthened competitiveness as a promising cell factory for many more applications.

Keywords: Yeast, Genome, Biotechnology, Tannic acid, n-butanol, Metabolism

\footnotetext{
* Correspondence: kunzeg@ipk-gatersleben.de; ncecile@grignon.inra.fr

${ }^{\dagger}$ Equal contributors

'Leibniz Institute of Plant Genetics and Crop Plant Research (IPK), Corrensstr.

3, Gatersleben D-06466, Germany

${ }^{2}$ AgroParisTech, Micalis UMR 1319, CBAl, Thiverval-Grignon F-78850, France

Full list of author information is available at the end of the article
}

\section{Biomed Central}

(c) 2014 Kunze et al.; licensee BioMed Central Ltd. This is an Open Access article distributed under the terms of the Creative Commons Attribution License (http://creativecommons.org/licenses/by/2.0), which permits unrestricted use, distribution, and reproduction in any medium, provided the original work is properly credited. The Creative Commons Public Domain Dedication waiver (http://creativecommons.org/publicdomain/zero/1.0/) applies to the data made available in this article, unless otherwise stated. 


\section{Background}

This paper discusses the sequencing of the genome of Arxula adeninivorans, a yeast of biotechnological interest. This species is currently exploited as biocatalyst for the synthesis of various biotechnological products such as tannases [1], 1-(S)-phenylethanol [2] or $\beta$-D-galactopyranoside [3], for the production of food with low purine content [4], and for the detection of estrogenic activity in various aqueous media [5,6]. It is also used as a host for the production of recombinant proteins, and as a donor for genes encoding valuable products $[7,8]$. Also developed as a microbial fuel cell, $A$. adeninivorans is shown to have a higher power output than Saccharomyces cerevisiae due to the production of an extracellular redox molecule [9].

This species was first described by Middelhoven et al. [10] who isolated a yeast strain from soil and designated it as Trichosporon adeninovorans CBS $8244^{\mathrm{T}}$. This strain was found to exhibit unusual biochemical activities, including the ability to assimilate a wide range of amines, adenine and several other purine compounds as a sole energy and carbon source. A second wild-type isolate (strain LS3 (PAR-4)) with characteristics similar to CBS $8244^{\mathrm{T}}$ was selected from wood hydrolysates in Siberia, and additional strains were later isolated from chopped maize silage or humusrich soil. A new genus name Arxula Van der Walt, Smith \& Yamada (candidaceae) was proposed for all of these strains $[11,12]$. No sexual reproduction has been observed in any of these strains, showing that they are all anamorphic ascomycetes. They also share common properties, such as nitrate assimilation and xerotolerance [13].

Kurtzmann and Robnett [14] revisited the phylogeny of yeasts and deduced that Arxula is a member of the Blastobotrys genus that contains both anamorphic and ascosporic species. Recent classifications consider this taxon as basal to the hemiascomycete tree in a region where genomic data are available for few other species [15]. This sequencing bias remains despite the number of recent publications of yeast genome sequences. For instance, Ogataea angusta (Hansenula polymorpha), Komagataella (Pichia) pastoris, Dekkera bruxellensis or more recently Kuraichia capsulata, use the basal yeast species Yarrowia lipolytica, which is the closest one of $A$. adeninivorans, as a single outgroup [16-19].

Thus, sequencing of the Blastobotrys (Arxula) adeninivorans genome was of interest in order to generate an additional landmark in the basal portion of the hemiascomycete tree and possibly resolve phylogenetic relationships among basal species. In addition, the sequence provides biotechnologists with complete information on the gene content of this species for which only 40 different protein entries are currently recorded in databases.

\section{Results}

\section{Genome architecture and main non-coding} genetic elements

The $A$. adeninivorans strain LS3 was selected because of its established biotechnological use [20]. Both mitochondrial and nuclear genomes were sequenced using the Sanger and 454 pyrosequencing approaches with different shotgun, plasmid and BAC libraries (Additional file 1). The circular mapping mitochondrial genome has a final size of 31,662 bp. It encodes 24 tRNA genes, 15 proteincoding genes including the seven NADH: ubiquinone dehydrogenase subunits of complex I, the genes encoding the RNA component of RNase P and the two subunits of the mitochondrial ribosomal RNA, as expected from the phylogenetic position of this species. All of these genes are transcribed from the same DNA strand except for the tRNA-Cys gene (Additional file 2).

After directed finishing phases, the $11.8 \mathrm{Mb}$ final assembly of the nuclear genome resulted in four contigs corresponding to the four chromosomes Arad1A, Arad1B, Arad1C and Arad1D, of 1,659,397, 2,016,785, 3,827,910, and 4,300,524 nt, respectively, as predicted from previous pulsed-field gel electrophoresis analyses [21] (Figure 1). $K$. pastoris and $Y$. lipolytica have four and six chromosomes respectively, while an average of eight and sixteen chromosomes is observed in protoploid and post-whole genome duplication species [22]. This may suggest a whole genome duplication event during early hemiascomycete evolution although there is presently no other evidence to support this hypothesis [23]. The four contigs contain no internal gaps and lack only terminal repeats at the telomeres. There is a single rDNA cluster, located approximately $75 \mathrm{~kb}$ upstream of the chromosome $\mathrm{D}$ right subtelomere. Based on 454 read counts, there are about 35 to 40 tandem repeats at this locus of the $18 \mathrm{~S}, 5.8 \mathrm{~S}$ and $26 \mathrm{~S}$ rRNA genes, the latter housing a 411-bp group-IC, selfsplicing intron [24]. We have left two copies of the rDNA units in Arad1D flanked by two artificial gaps of 874 " $N$ ". As in $Y$. lipolytica, the $5 \mathrm{~S}$ rRNA genes are not included in the rDNA repeat, but occur as 30 copies dispersed throughout the genome (Table 1). A set of 46 tDNAs encoded by 147 tRNA genes was identified and confirmed that $A$. adeninivorans follows the regular eukaryotic-type sparing rules to read CTY Leu and CGA Arg codons [25]. Forty seven genes encoding snRNAs or snoRNAs were identified: the small nuclear RNAs (U1, U2, U4, U5 and U6), the RNA components of the RNase P, and of the signal recognition particle, as well as $14 \mathrm{H} / \mathrm{ACA}$ and 33 C/D snoRNAs (Additional file 3). Additionally, three thiamine pyrophosphate (TPP) riboswitch sequence candidates were found in the $5^{\prime}$ region from homologs of S. cerevisiae THI4 (YGR144W), UGA4 (YDL210W) and DUR3 (YHL016C), namely ARAD1R43560g, ARAD1D08074g and ARAD1B12386g; they show a remarkable conservation 


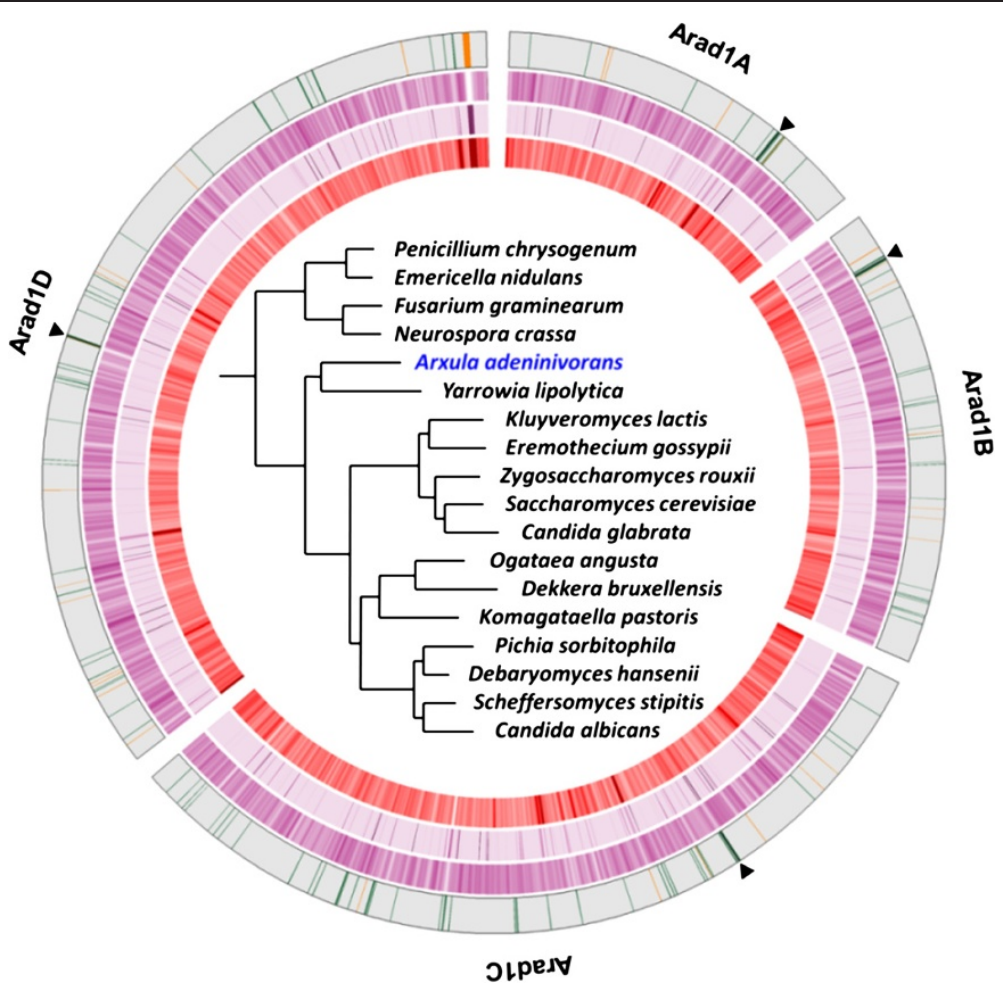

Figure 1 Circos map of the complete nuclear genome of A. adeninivorans LS3. Chromosome structure (the outermost circle - circle 1): presumed centromeric positions are indicated by black bands and black triangles outside the circle, and tRNA and rRNA genes by green and orange bands, respectively. Genes (circle 2): density of genes in the filtered gene set across the genome, from a gene count per $15 \mathrm{~kb}$ sliding window at $5 \mathrm{~kb}$ intervals. Repeat content (circle 3): for creating k-mer density ring, k-mers with length $=20$ in whole genome using jellyfish program v. 1.1.1 (http://www.cbcb.umd.edu) were counted, a position map of k-mer count was created, k-mers counted in blocks of 3 kb were divided by 3,000 and the data was plotted using Circos's heatmap. 454 reads mapped to chromosomes (circle 4): density of 454 reads mapped to chromosomes, from a 454 read count per $9 \mathrm{~kb}$ sliding window at $3 \mathrm{~kb}$ intervals. Underlined blocks indicate alignment in the reverse strand. In the centre of the Circos map the phylogenetic relationship of A. adeninivorans is presented as inferred by gene tree parsimony analysis of the complete

A. adeninivorans phylome. $\mathrm{k}$-mer, tuple of length $\mathrm{k}$.

of known structural domains and sequence motifs [26]. A single transposable element was identified on chromosome B (Taa3, ARAD1B13860t) that belongs to the Gypsy superfamily of Long Terminal Repeat (LTR) retrotransposons with the two gag and pol open reading frames separated by a minus 1 frameshift as seen in the homologous element Tyl6 of Y. lipolytica [27]. The single copy of Taa3 was found 13 bp upstream of a tRNA gene, suggesting a possible specificity of insertion [28]. Only three relics of solo LTRs were identified in the genome, which implies that Taa3 has low activity.

Putative centromeres were identified within one region per chromosome with a conspicuous $\mathrm{G}+\mathrm{C}$ (Guanine + cytosine) bias defining approximately $6 \mathrm{~kb} \mathrm{G}+\mathrm{C}$ troughs,

Table 1 General features of A. adeninivorans LS3 nuclear genome

\begin{tabular}{|c|c|c|c|c|c|c|c|c|c|c|c|c|}
\hline & \multicolumn{3}{|c|}{ Chromosome } & \multicolumn{3}{|c|}{ CDS } & \multirow[t]{2}{*}{ Pseudo-genes } & \multirow[t]{2}{*}{ i-genes } & \multirow[t]{2}{*}{ Introns } & \multirow[t]{2}{*}{ tRNA } & \multirow[t]{2}{*}{ 5S rRNA } & \multirow[t]{2}{*}{ ncRNA } \\
\hline & Size & $G+C \%$ & Coding $\%$ & $\#$ & $\mathbf{G}+\mathbf{C} \%$ & Mean Size (nt) & & & & & & \\
\hline AradiA & 1659397 & 48.2 & 73.2 & 871 & 49.6 & 1395 & 3 & 84 & 106 & 13 & 4 & 9 \\
\hline AradiB & 2016785 & 48.4 & 72.6 & 1051 & 49.8 & 1394 & 5 & 109 & 135 & 31 & 8 & 5 \\
\hline Arad1C & 3827910 & 48.0 & 75.8 & 1991 & 49.2 & 1457 & 11 & 260 & 343 & 54 & 6 & 16 \\
\hline Arad1D & 4300524 & 48.1 & 73.6 & 2203 & 49.3 & 1437 & 14 & 250 & 330 & 49 & 12 & 15 \\
\hline Total & 11804616 & 48.1 & 74.1 & 6116 & 49.4 & 1430 & 33 & 703 & 914 & 147 & 30 & 45 \\
\hline
\end{tabular}

CDS, coding DNA sequence; $G$, guanine, $C$, cytosine; ncRNA, non coding RNA. 
with a $\mathrm{G}+\mathrm{C}$ content of 31 to $33 \%$ as compared to $48 \%$ for the whole genome. Like those of $Y$. lipolytica, they share features of both regional centromeres found in yeasts of the CTG group, and of point centromeres characteristic of Saccharomycetaceae [29] (Additional file 4).

\section{Protein-coding genes, pseudogenes, introns}

A total of 6,116 protein-coding genes and 33 pseudogenes were identified. This is slightly less than reported for $Y$. lipolytica or Debaryomyces hansenii, but significantly more than for the Saccharomycetaceae species (Table 2). The frequency of pseudogenes is one of the lowest reported in hemiascomycetes, while gene density is one of the highest.

A total of 4,815 (78.7\%) genes were assigned to gene ontology (GO) terms: 3,853 genes to molecular functions, 2,626 to cellular components and 3,308 to biological processes. In the biological processes, the largest fraction of genes, 1,351 (22.1\%), was assigned to metabolism, while in the molecular functions the largest category was represented by genes encoding catalytic activities. The GO slim categories of $A$. adeninivorans are presented in Additional file 5. InterPro domains were detected in 5,147 (84.2\%) proteins corresponding to 459 distinct Pfam domains. A secretion signal peptide of type I or type II was predicted in 957 (15.6\%) gene products, including Atan1p and Alip1p that were previously characterized experimentally by $\mathrm{N}$-terminal sequencing and mass spectrometry (MS) analysis [32,33]. Transmembrane helices were found in 1,271 (20.8\%) proteins. An Enzyme Commission (EC) number was assigned to 676 (11.1\%) genes. We assigned 884 (14.4\%) genes to 98 metabolic pathways present at the Kyoto Encyclopedia of Genes and Genomes (KEGG) with the highest number of genes related to purine metabolism. Blast2GO BLASTx alignments using the NCBI NRPEP database confirmed that the closest matches to A. adeninivorans genes were very often found in Y. lipolytica (Additional file 5).

Spliceosomal introns are more frequent than in Saccharomycetaceae or in Debaryomycetaceae, but in the same range as reported for Y. lipolytica (914 versus 1119, Table 2). In this latter species, introns are characterized by a very short distance between the 3 ' splicing site and the branch point, but have in contrast retained the ancestral consensus hemiascomycete 5 ' splicing site (GTAAGT). Finally, multiintronic genes tend to be more frequent in $A$. adeninivorans than in $Y$. lipolytica (21.5\% vs. $11.5 \%)$. For additional information, see Additional file 6 and Genosplicing [31].

\section{Phylogeny and synteny conservation}

A phylogenetic tree was reconstructed for each $A$. adeninivorans protein-coding gene, the so-called phylome, and used to identify orthology and paralogy relationships among related species [34]. This comprehensive collection of evolutionary histories is publicly available at PhylomeDB

Table 2 Annotated features of $\boldsymbol{A}$. adeninivorans when compared to other representative Hemiascomycetes

\begin{tabular}{|c|c|c|c|c|c|}
\hline $\begin{array}{l}\text { Species } \\
\text { Strain }\end{array}$ & $\begin{array}{l}\text { S. cerevisiae } \\
\text { S288c }\end{array}$ & $\begin{array}{l}\text { L. thermotolerans } \\
\text { CBS } 6340\end{array}$ & $\begin{array}{l}\text { D. hansenii } \\
\text { CBS } 767\end{array}$ & $\begin{array}{l}\text { Y. lipolytica } \\
\text { E150 }\end{array}$ & $\begin{array}{l}\text { A. adeninivorans } \\
\text { LS3 }\end{array}$ \\
\hline Chromosome number & 16 & 8 & 7 & 6 & 4 \\
\hline \multicolumn{6}{|l|}{ Genome } \\
\hline Ploidy & $n$ & $2 n$ & $n$ & $\mathrm{n}$ & $n$ \\
\hline Size & 12.1 & 10.4 & 12.2 & 20.5 & 11.8 \\
\hline Average $\mathrm{G}+\mathrm{C}$ content (\%) & 38.3 & 47.3 & 36.3 & 49.0 & 48.1 \\
\hline Genome coding coverage (\%) & 70.0 & 72.3 & 74.2 & 46 & 74.1 \\
\hline \multicolumn{6}{|l|}{ CDS } \\
\hline Total CDS (pseudo) & 5769 & $5094(46)$ & $6272(129)$ & $6449(137)$ & $6116(33)$ \\
\hline Average G + C (\%) & 39.6 & 49.2 & 38.0 & 52.9 & 49.4 \\
\hline Average size (aa) & 485 & 492 & 479 & 476 & 477 \\
\hline i-genes & 287 & 278 & 420 & 984 & 703 \\
\hline Introns & 296 & 285 & 467 & 1119 & 914 \\
\hline Total tRNA genes & 274 & 229 & 205 & 510 & 147 \\
\hline Total snRNA & 6 & 5 & 5 & 6 & 5 \\
\hline Total snoRNA & 77 & 43 & ND & ND & 37 \\
\hline rDNA clusters & 1 (internal) & 1 (internal) & 3 (internal) & 6 (subtelomeric) & 1 (internal) \\
\hline Total dispersed 5S rRNA genes & 0 & 0 & 0 & 116 & 30 \\
\hline
\end{tabular}

snRNA, small nuclear ribonucleic acid; snoRNA, small nucleolar ribonucleic acid; CDS, coding DNA sequence; $G+C$, guanine and cytosine; aa, amino acids; i-genes, intron-containing genes; ND, not-determined. Data from S. cerevisiae, Lachancea thermotolerans, D. hansenii and $Y$. lipolytica were taken from [30]; data on intron-containing genes from [31]. 
[35]. Species phylogenies were computed on a set of concatenated orthologs and using a super tree approach combining all individual gene phylogenies. The two methods gave the same topology, in which $A$. adeninivorans groups with $Y$. lipolytica (Additional file 7), although the two species have greatly diverged. For instance, our analyses identified 2,520 A. adeninivorans proteins that lack an ortholog in Y. lipolytica, 591 of which do not even have a homolog in that species. For 121 proteins we could only detect homologs in Pezizomycotina genomes (Additional file 8). Horizontal gene transfer between prokaryotes and fungi was detected using a published pipeline [36], which pinpointed six candidates with putative enzymatic function that are likely to have been transferred from prokaryotes to Arxula (Additional file 8). Few genes of bacterial origin have been reported in Saccharomycotina so far, but most of them encode metabolic enzymes with important physiological roles that may facilitate host adaptation to biotope variations (see [36,37] for large-scale trans-kingdom transfer in fungi).

The number of conserved gene blocks between $A$. adeninivorans and other genomes ranged from 300 with $S$. cerevisiae to $>800$ with $Y$. lipolytica, and was roughly proportional to the mean percentage of protein similarity, as is expected when species have greatly diverged. Indeed, in the comparison between $Y$. lipolytica and $A$. adeninivorans, 92\% of the blocks contained less than four genes, showing that there is no large-scale conservation of synteny (Additional file 7).

\section{Gene families: expansion and contraction}

The gene trees in the phylome were scanned to detect and date duplication events [38]. With an average of $0.253 \mathrm{du}$ plications per gene in the specific lineage leading to Arxula, this genome does not seem to contain a large amount of duplications. This is nevertheless greater than the 0.015 value found in the common ancestor of $Y$. lipolytica and A. adeninivorans (Additional file 9). Most Arxulaspecific expansions are not very large (between three and nine sequences) and correspond to peptidases, transporters, dehydrogenases and some proteins related to nitrogen metabolism (Additional file 9). One expansion, however, contains over 100 members of unknown function and no homologs in any database, which is to our knowledge the largest gene family described in yeast (Figure 2 and Additional file 9).

There are fewer transporters in $A$. adeninivorans than in for example $D$. hansenii or $Y$. lipolytica, but some have undergone strong amplification. Remarkably, sugar transporters appear overrepresented in this species: there are 60 members of the Sugar Porter family, which is three times as many as in Kluyveromyces lactis or K. pastoris, and 1.8 times more than in S. cerevisiae (Additional file 10). These include 15 glycerol: $\mathrm{H}^{+}$symporters, paralogs of the S. cerevisiae singleton STL1, compared to eight in the osmotolerant yeast $D$. hansenii, which may reflect the salt tolerance of $A$. adeninivorans. The ability to use various carbon sources is highlighted by the abundance of high affinity glucose: $\mathrm{H}^{+}$symporters (10 members), maltose: $\mathrm{H}^{+}$ symporters (10 members), lactose permeases (four members versus one in $K$. lactis and $D$. hansenii), allantoate permeases (six members), and of facilitators for the uptake of xylose (six members), quinate (four members), fructose (four members) and myo-inositol (three members). Surprisingly, there are few glucose uniporters (two members, versus eighteen and four in S. cerevisiae and D. hansenii, respectively) and few sugar sensors. High-affinity nicotinic acid transporters (six members), polyamine transporters (15 members) and nitrate/nitrite permeases (three members) are also amplified (Additional file 10).

About $10 \%$ of the duplicated genes (213/2285) are organized in tandem gene arrays (TGAs), mostly as arrays of two genes. These arrays are sometimes entirely duplicated on the same or on different chromosome(s), a situation that so far remains unusual. The mechanism involved has given rise to the largest protein family in yeasts as mentioned above. BLASTn searches indicated that coding and intergenic regions of duplicated TGAs are highly conserved at the nucleotide level, suggesting propagation of ancestral tandems by segmental duplication at ectopic positions (Figure 2 and Additional file 11).

\section{Mating genes}

A. adeninivorans LS3 is only known to reproduce asexually [20], yet a $M A T$ locus was identified on chromosome $\mathrm{D}$ as is the case in many asexual species [40]. The region around the mating type locus is conserved between $Y$. lipolytica and $A$. adeninivorans, while it is rearranged in basal species such as Lipomyces starkeyi, filamentous fungi, and in species that emerged later, such as K. pastoris or K. lactis (Figure 3). The MAT locus encodes a homolog of the transcriptional factor Mat $\alpha 1$ present in other yeast species (ARAD1D19294g, MTAL1), with a canonical DNA binding domain and a C-terminal extension partially conserved in $Y$. lipolytica, but absent from other species (Additional file 12). There is no Mat $\alpha 2$ coding sequence (MTAL2) contrary to the situation reported in other heterothallic yeast species such as $S$. cerevisiae and $Y$. lipolytica. The presence of only MTAL1 at the MATalpha locus is, however, found in several sexually competent filamentous fungi and yeasts such as Aspergillus nidulans, Clavispora lusitaniae, Meyerozyma guillermondii, Scheffersomyces stipitis or D. hansenii [40]. Whether A. adeninivorans is asexual or not is still an open question. Either $A$. adeninivorans is truly asexual and the loss of MTAL2 may be the cause, or alternatively, A. adeninivorans is sexual but strains of the opposite mating type have not yet been identified, thus preventing successful mating. 

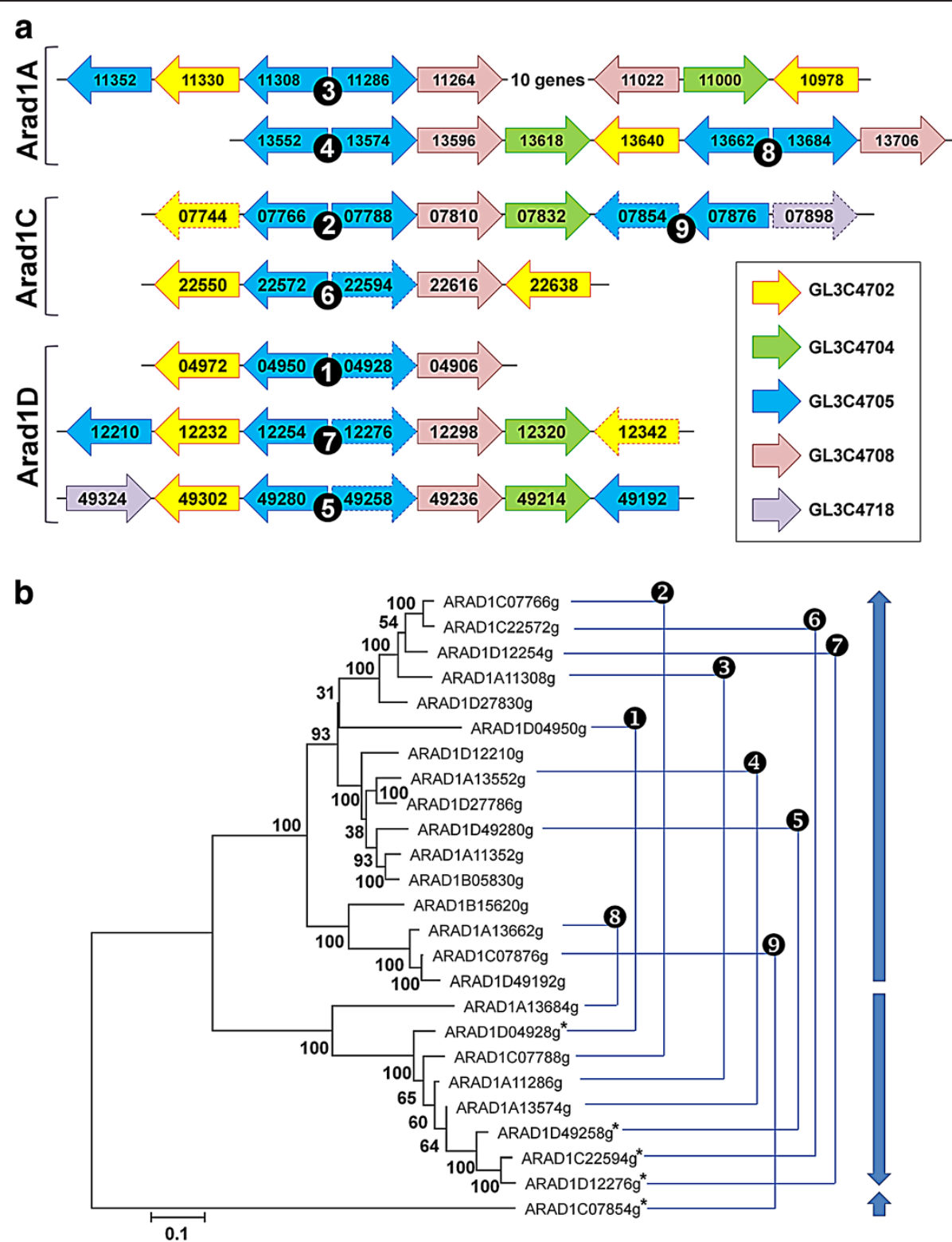

Figure 2 Tandem gene arrays in A. adeninivorans. (a) Intermingled families. A. adeninivorans chromosomes are indicated on the left. Gene members of TGAs are depicted by boxed arrows colored according to their family. Family numbers refer to the Génolevures classification as shown in the legend in the box on the right. Pseudogenes are indicated by dotted lines. The GL3C4705 family is the largest one. Most of its members are tail-to-tail inverted tandem repeats, numbered from one to nine in black disks. (b) Neighbor-joining tree based on the muscle [39] alignment of positions one and two of the codons. Robustness of the tree is indicated by 100 bootstrap values calculated with a maximum composite likelihood model with uniform rates. Thin blue lines indicate pairs in inverted repeats of GL3C4705 family; heavy blue lines indicate relative orientation of genes in inverted repeats (see Additional file 11 for additional information).

A search for genes involved in mating, meiosis and sporulation in S. cerevisiae identified the presence of most genes conserved in the sexual species $D$. hansenii, K. pastoris and Y. lipolytica (Additional file 13). For example, out of 368 genes tested, 292 were conserved in $Y$. lipolytica and 288 in A. adeninivorans. Candidates for the mating pheromones MFa and MF $\alpha$ and of their cognate receptors as well as for the signaling cascade were identified, confirming that A. adeninivorans is either still sexually active or has lost this ability only recently (Additional file 14).

\section{Metabolic pathways}

A. adeninivorans is described as having a wide substrate spectrum that includes the assimilation of many nitrogenous and aromatic compounds such as nitrate and nitrite, purines, tannins and benzoic acid derivatives $[13,41,42]$. The ability to degrade purine compounds is reported in all 


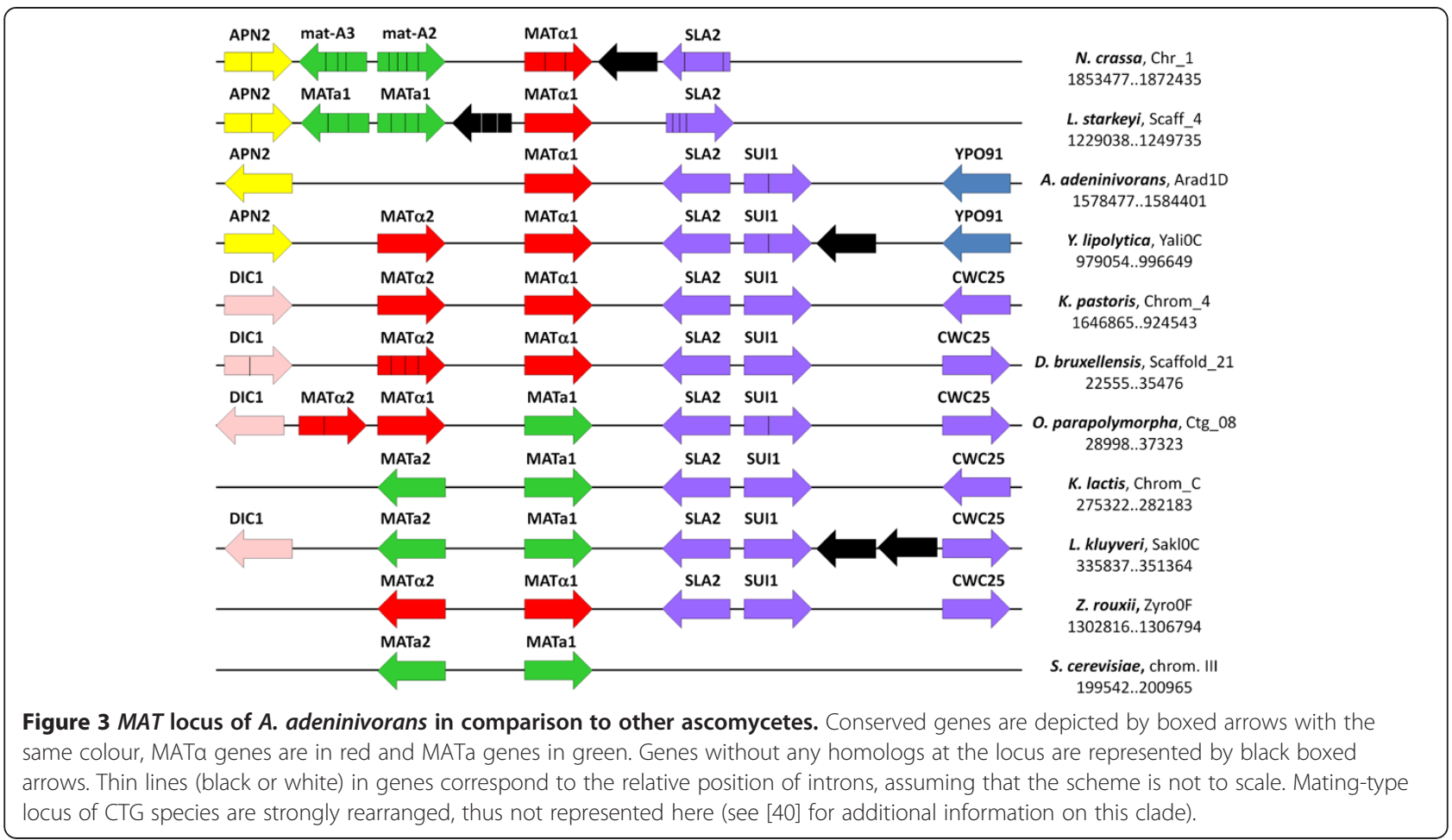

kingdoms and can occur either aerobically or anaerobically in separate pathways. In the aerobic pathway, the critical step in the degradation of purine bases is the oxidation of hypoxanthine and xanthine to uric acid, catalyzed by xanthine oxidase and/or dehydrogenase. The various purine-degradative pathways are unique and differ from other metabolic pathways because they may serve quite different purposes, depending on the organism or tissue. While some organisms degrade the naturally occurring purines to $\mathrm{CO}_{2}$ and ammonia, others contain only some of the steps of the purine degradation pathways, resulting in partial degradation of purines or certain intermediary catabolites [43].

Purine catabolism is a characteristic feature of $A$. adeninivorans [13]. The purine nucleosides (adenosine, inosine, xanthosine and guanosine) are transported across the membrane and into the cytoplasm by a purine permease. They are then converted to adenine, hypoxanthine, xanthine and guanine, further degraded to uric acid and, after transport into the peroxisomes, to urea. All corresponding genes of this pathway are localized on different chromosomes and are induced by adenine and other pathway intermediates $[4,44]$. Interestingly, an adenosine deaminase, needed to transform adenosine to inosine in animals and human, is absent (Figure 4). This pathway allows $A$. adeninivorans to use all of these purine derivatives as nitrogen and carbon sources $[4,44]$.
As in Ogatea (Hansenula) polymorpha [45] and in Kuraishia capsulata [18], a cluster of genes encoding a nitrate transporter, a nitrate reductase and a nitrite reductase has been previously identified in $A$. adeninivorans [46]. Genome data indicate that nitrate transporter encoding genes form a three member family, two of which are part of the nitrate cluster.

Microarrays were designed based on the complete genome data of $A$. adeninivorans to analyze gene expression changes before and after a shift from yeast minimal medium $(Y M M)+2 \%$ glucose with $\mathrm{NaNO}_{3}$ to YMM medium with adenine as the nitrogen source. A significant down regulation of the genes involved in nitrate metabolism was observed two hours after the shift. Key components of the purine degradation pathway on the other hand, clearly showed an increased activity (Figure 4). This provides further insight into the regulation of purine degradation by $A$. adeninivorans and emphasizes the possibility of using transcriptomic approaches to identify candidate genes for new biotechnological applications. Arxula specificities of the purine degradation pathway include the regulation of the respective genes. Activity tests, qRT-PCR experiments and microarray assays with xanthine dehydrogenase inducers demonstrated strong gene inducibility when cells were cultured on hypoxanthine and adenine and a lower level of induction with uric acid as the sole nitrogen source. However, enzyme induction by purines stops after 


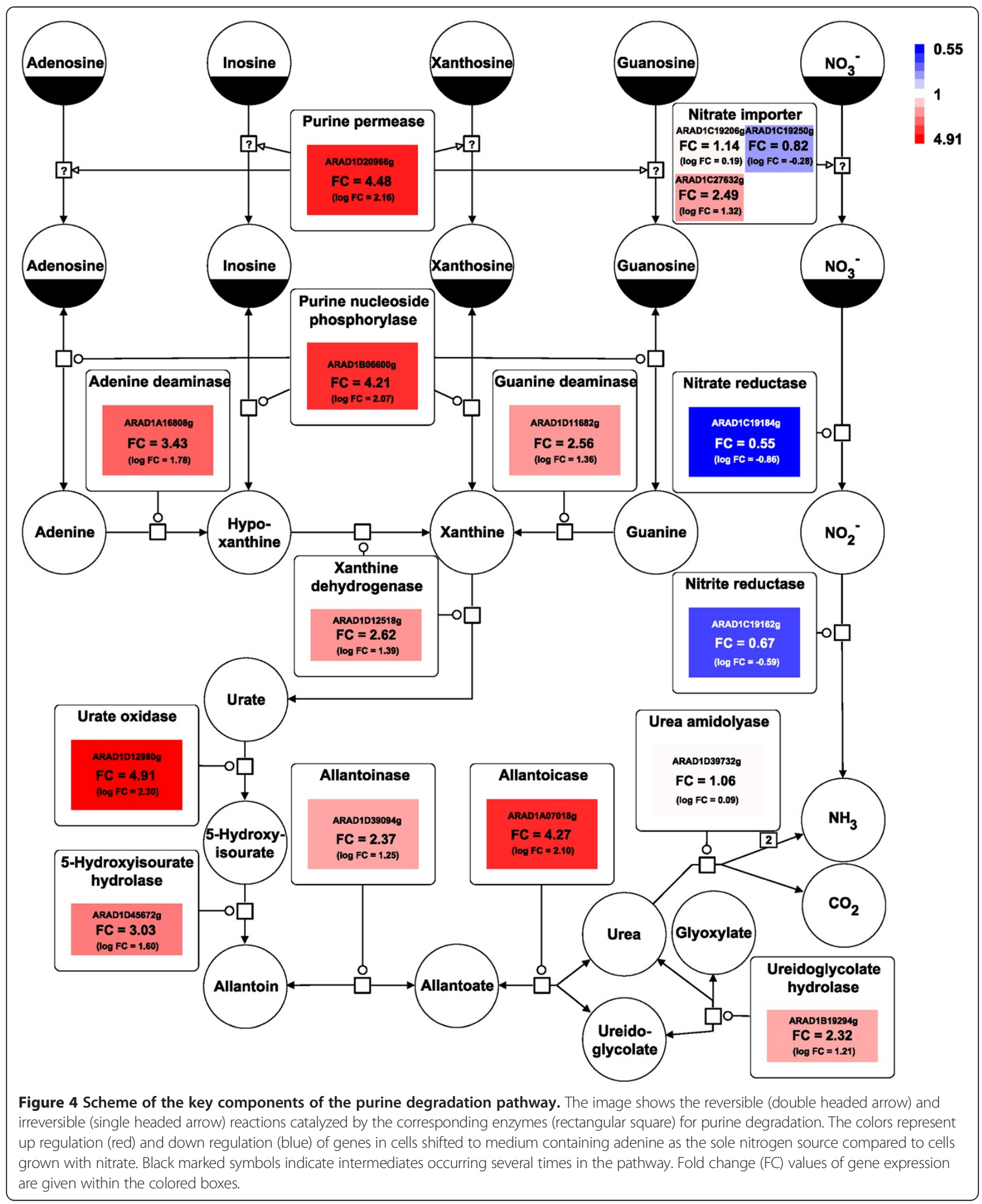

supplementing the medium with $\mathrm{NH}_{4}{ }^{+}$or $\mathrm{NO}_{3}{ }^{-}$as nitrogen sources, which is in contrast to the situation in $N$. crassa where the enzyme is induced in the presence of
$\mathrm{NO}_{3}{ }^{-}$, but not with $\mathrm{NH}_{4}{ }^{+}$. It is known that in $A$. nidulans, $\mathrm{NH}_{4}^{+}$inactivates the GATA factor AreA, which is responsible for expression of the urate-xanthine transporter [47]. 
It is not clear which mechanism triggers the repression with $\mathrm{NH}_{4}{ }^{+}$and $\mathrm{NO}_{3}{ }^{-}$in $A$. adeninivorans [4].

Tannin, a plant polyphenol molecule, is widely distributed in the plant kingdom where it protects plants against attack by parasites and herbivores. It inhibits the activity of enzymes by binding and precipitation and is to a greater or lesser extent recalcitrant to biodegradation [48]. While tannins are growth inhibitors for most microorganisms, a few bacteria, fungi and yeast such as D. hansenii, Mycotorula japonica or Candida sp. are capable of exploiting tannins as a carbon and/or energy source for growth [49-51]. A. adeninivorans is one of these yeasts that use tannic acid and gallic acid as carbon sources [52]. Genes encoding tannases (ATAN1 ARAD1A06094g, ATAN2 - ARAD1A19822g), gallate decarboxylase (AGDC - ARAD1C45804g) and catechol 1,2 dioxygenase (ACDO - ARAD1D18458g) have been identified and His-tagged recombinant enzymes and corresponding gene mutants were used to confirm the activity of these enzymes (data not shown). This demonstrated that the tannic acid catabolism pathway enables this yeast to assimilate tannic acid and other hydroxylated derivatives of benzoic acid by non-oxidative decarboxylation. All suitable derivatives require an hydroxide group at the $m$ or $p$ position of the carboxylic acid (Additional file 15). Interestingly, $A$. adeninivorans is thus the first eukaryote known to synthesize two tannases, one extracellular (Atan1p) [32] and one cell-wall localized (Atan2p - data not shown) which permits effective degradation of extracellular tannic acid. Both enzymes are able to remove gallic acid from both condensed and hydrolysable tannins. Substrate specificity, biochemical parameters (temperature optimum 35 to $40^{\circ} \mathrm{C}, \mathrm{pH}$ optimum at ca. $6.0)$ and nearly complete extracellular localization ( $\geq 97 \%)$ distinguish Atan1p as an important industrial enzyme. First, transgenic tannase producer strains were constructed with a constitutively expressed ATAN1 module integrated into a chromosome. In fed-batch fermentation experiments, the transgenic strain produced 51,900 U/L of tannase activity after $42 \mathrm{~h}$ with a dry cell weight of $162 \mathrm{~g} / \mathrm{L}$ [1].

Another uncommon substrate used by this yeast is nbutanol. The n-butanol degradation pathway has not previously been reported to exist in eukaryotes. Genome mining suggests that $\mathrm{n}$-butanol is oxidized to butyraldehyde by an alcohol dehydrogenase (Aadh1p, AADH1 ARAD1B16786g) that has a high substrate specificity, and then to butyric acid by two aldehyde dehydrogenases (Aald2p, AALD2 - ARAD1B17094g; Aald5p, AALD5 ARAD1C17776g). The last steps involve an acyl-CoA ligase, a cytoplasmic acyl-CoA carnitine acyltransferase and a peroxisomal acyl-CoA carnitine acyltransferase for butyryl-carnitine synthesis via a butyryl-CoA intermediate that is transported from the cytoplasm to peroxisomes or mitochondria for ß-oxidation. A special feature of this pathway is that the synthesis of butyryl-CoA from butyric aldehyde is a one-way reaction since the aldehyde dehydrogenase and acyl-CoA ligase steps are not reversible (Figure 5).

\section{Conclusion}

The complete sequence of $A$. adeninivorans nuclear and mitochondrial genomes has been provided. High-quality genomes in early-diverging Saccharomycotina are scarce and that sequence will allow further fundamental studies on comparative genomics, evolution and phylogenetics. It will also allow the deciphering of a new mechanism of genome modeling through TGA duplication. Arxula is able to assimilate a wide spectrum of $\mathrm{C}$ and $\mathrm{N}$-sources, which includes not only conventional substrates such as glucose, xylose, and starch but also rarely metabolized substances as n-butanol, tannic acid and protocatechuate. Sequencing its genome revealed protein components of these pathways, which had previously remained unexplored in yeast, offering clues for further biotechnological developments. In the course of identifying alternative microorganisms for biotechnological interest, $A$. adeninivorans has already proved its competitiveness in white biotechnology, and is further strengthened as a promising cell factory for many more applications.

\section{Materials and methods}

\section{Genome sequencing and assembly}

The genome of $A$. adeninivorans LS3 was sequenced independently by the Genoscope (Evry, France) using the capillary Sanger technology and by IPK (Gatersleben, Germany) using the 454 Roche methodology (GS-FLX Titanium version).

For the Sanger technology, a shotgun sequencing strategy using three different clone libraries and capillary Sanger sequencing was used to obtain a $12 \times$ coverage of the complete genome. For two of three libraries, genomic DNA was fragmented by mechanical shearing and $3 \mathrm{~kb}$ (A) or $10 \mathrm{~kb}$ (B) inserts were respectively cloned into pcdna2.1 (Invitrogen, Saint Aubin, France) and pCNS (pSU18 derived) plasmid vectors. In addition, a large insert (25 kb) BAC library (C) was constructed from Sau3A partial digest and cloned into pBeloBAC11. Vector DNAs were purified and end-sequenced (124,032 reads (A), 61,440 reads $(B), 5,376$ reads $(C)$ ) using dye-terminator chemistry on ABI3730 sequencers. The reads were assembled using the whole genome shotgun assembler ARACHNE and the chromosome sequences were individually reassembled using the Phred/Phrap/Consed software package. For the finishing step, we used primer walking of clones, PCR amplifications and in vitro transposition technology [Template Generation System ${ }^{\mathrm{Tm}}$ II Kit (Fisher Scientific, Illkirsh, France) or Hypermu $<$ Kan-1 $>$ (Tebu-Bio, Le Perray-enYvelines, France), corresponding to 814, 33 and 17,975 
Figure $\mathbf{5}$ Schematic overview of the $\mathbf{n}$-butanol degradation pathway in A. adeninivorans. Arxula is able to use $n$-butanol as the sole carbon and energy source, by converting it into the central metabolite acetyl-CoA by ß-oxidation, to finally generate succinate in the peroxisomes. A genome-mining approach led to the proposal of the pathway shown here. The figure shows the reversible (double headed arrow) and irreversible (single headed arrow) reactions catalyzed by the corresponding enzymes (rectangular square) and the cofactors (ATP/AMP, NAD+/NADH) necessary for $n$-butanol degradation. Black marked symbols indicate intermediates occurring several times in the pathway. AMP, Adenosine monophosphate; ATP, Adenosine triphosphate; CoA, coenzyme A; NAD, Nicotinamide adenine dinucleotide; PP, phosphate.

reads, respectively. The final assembly consisted of four scaffolds larger than $1 \mathrm{Mb}$, hereafter referred to as chromosomes, and nine shorter contigs of a size ranging from 4 to $120 \mathrm{~kb}$, including four mitochondrial scaffolds. Four of the remaining contigs were later incorporated at chromosome ends in the final assembly using data obtained from the 454 assembly. The mitochondrial genome sequence was assembled as a circular map using Sanger and 454 contigs and manually validated using single reads obtained with the Sanger technology. A. adeninivorans genome sequence data have been deposited at EMBL under the accession number PRJEB4557 [EMBL:PRJEB4557].

The shotgun library of $A$. adeninivorans for sequencing on Roche 454 GS FLX Titanium sequencer was prepared using $5 \mu \mathrm{g}$ of genomic DNA. Based on random cleavage of the genomic DNA with subsequent removal of small fragments with Agentcourt AMPure SPRI beads (Beckman Coulter, Krefeld, Germany), the resulting single stranded DNA (ssDNA) library showed a fragment distribution between 300 and $1000 \mathrm{bp}$. The optimal amount of ssDNA library input for the emulsion (emPCR) was determined empirically through 4 small-scale titrations with one, two, four and eight copies per bead (cpb). Finally, one cpb was used for the large-scale experiment. One individual emulsion PCR (two cups, one full emPCR-Kit LV (Roche Applied Science, Mannheim, Germany) was carried out to generate 5.7 million DNA-carrying beads for two-region sized $70 \times 75$ PicoTiterPlates (Roche Applied Science, Mannheim, Germany) and each region was loaded with 2 million DNA-carrying beads. Two read sets were thus generated totaling 1,074,025 reads. This resulted in $542.3 \mathrm{Mb}$ of sequence data (45-fold genome sequence coverage) with an average read length of $505 \mathrm{bp}$. Assembly was performed using the Newbler software (v2.3) within the Roche 454 suite package, MIRA multi-pass DNA sequence data assembler/mapper (v3.0.2) and CLC Bio assembler. To allow comparisons between the assemblies of different assembly programs, singletons and contigs shorter than $100 \mathrm{bp}$ were discarded before subsequent analysis. Standard metrics describing the assembly, such as the total bases used in a assembled contigs, the amount of contigs longer than $300 \mathrm{bp}$, 
$500 \mathrm{bp}, 1 \mathrm{~kb}, 2 \mathrm{~kb}$ and $5 \mathrm{~kb}$, number of base pairs in the largest contig and N50 contig length (the smallest contig size in which half the assembly is represented) were used to compare the assembly programs. The highest number of contigs was produced by MIRA but only 161 contigs were longer than one kilobase pair. While Newbler and CLC Bio assemblers constructed longer contigs, however the longest contig was generated by MIRA (Additional file 1).

\section{Mapping of GS FLX shotgun reads and contigs to assembled chromosomes}

To assess the quality of the final assembled genome, the 454 reads were mapped onto the chromosomes using the Burrows-Wheeler Alignment tool BWA [53]. Two statistics were extracted from the mappings using Samtools [54]: the percentage of reads that mapped on the assembly and the percentage of reads that mapped to each chromosomes. The quality of the final assembled genome was estimated using the dot-plot analysis which was performed using Nucmer software (NUCleotide MUMmer v3.1 [55]). The dot-plot alignment was generated by comparison of all assembled chromosomes and contigs.

Mapping of 454 reads was used to estimate the gene copy number by computing the number of tags mapping to unique regions of the genome. For this purpose, sequences of $21 \mathrm{~A}$. adeninivorans genes, deposited in GenBank (NCBI), were used in BLASTn searches together with the set of all 454 reads using three BLAST e-value cutoff $=\mathrm{e}-10, \mathrm{e}-50$ and e-100 to improve search specificity. The analysis of the gene copy number was performed using the formula: GeneCopyNumber $=$ (Number of BLASTn hits * Average read length $) /$ (Gene length * 454 sequence coverage).

\section{Genome annotation}

Non-protein coding and protein-coding gene models were predicted according to Louis et al. [56]. All translations of models longer than 80 codons were compared against the proteomes of $Y$. lipolytica and $S$. cerevisiae as well as Uniprot-Fungi using BLASTp. In addition, the gene models were compared to position-specific scoring matrix (PSSM) representative of Genolevures protein families [57] with PSI-tBLASTn (Position-Specific Iterated BLAST). Preannotated gene models were then examined for validation in the framework of the Génolevures proprietary Magus annotation system by a community of curators, in three phases: (i) curation of models with PSI-tBlastn hits, as possible new members of protein families, for homogeneity of annotation, (ii) curation of other models, (iii) final finishing through contig walk by a single curator in charge. At any phase, curators could add or modify gene models.

Circos [58] was used for illustration of nuclear genome data such as: chromosome structure (position of centromeres, tRNA and rRNA genes), density of genes across the genome, content of repeat DNA, 454 reads mapped to chromosomes, syntenic blocks between $A$. adeninivorans and genomes of $Y$. lipolytica, $K$. pastoris and $S$. cerevisiae.

Functional annotation of genes according to the GO terms, EC numbers and the KEGG pathway were performed for each $A$. adeninivorans CDS using the Blast2GO software suite. Protein domains were detected by InterProScan with various databases (BlastProDom, FPrintScan, HMM-PIR, HMM-Pfam, HMM-Smart, HMM-Tigr, PatternScan, SuperFamily, HMM-Panther and Gene3D) through the European Bioinformatics Institute Web Services. Signal peptide and transmembrane helices were predicted by SignalP v.3.0's neural network and hidden Markov model tools [59] and TMHMM, respectively.

\section{Protein families}

The classification of $A$. adeninivorans protein sequences into protein families was performed along two procedures. First, protein sequences were tentatively incorporated into protein families defined in the previous round of Génolevures genome annotation using PSI-BLAST with relaxation factors based on family dispersion [30]. Second, the sequences rejected by the procedure were pooled with the sequences of the nine species already present in the Génolevures database which are not members of any protein family and a clustering with OrthoMCL [60] was applied to define new families.

\section{Phylome reconstruction}

The phylome, a complete collection of phylogenetic trees for each gene in $A$. adeninivorans, was reconstructed. Seventeen additional species were included in the phylome: three Pezizomycotina species and fourteen Saccharomycotina species. The phylome was reconstructed using a previously described pipeline [35]. Briefly, for each gene encoded in $A$. adeninivorans, a BLAST search was performed against the proteome database containing the 18 proteomes. Results were filtered according to e-values $<1 \mathrm{e}-05$ and minimal overlaps with hit sequences at $50 \%$ of the query length. A maximum of 150 matches were accepted for each $A$. adeninivorans protein. Multiple-sequence alignments were performed in forward and reverse orders [61], using three programs: Muscle [39] v3.8.31, MAFFT v6.814b [62] and DIALIGN-TX [63]. The six resulting alignments were then combined using M-COFFEE (T-Coffee v8.80) [64] and trimmed using trimAl [65] v1.3 (consistency cutoff: 0.1667; gap score cutoff: 0.1 ). Model selection for phylogenetic tree reconstruction was performed by reconstructing neighbour joining trees using BioNJ [66] with different models (JTT, WAG, MtREV, VT, LG, Blosum62, CpREV and DCMut) and then the two best models according to the AIC criterion [67] were chosen. The selected models were used to reconstruct maximum likelihood trees using phyML [68]. In all cases, a discrete gamma-distribution model with four rate categories plus invariant positions was used, the gamma 
parameter and the fraction of invariant positions were estimated from the data. A total of 4,992 trees were reconstructed. Trees and alignments are stored in the database phylomeDB with the PhyID code 178.

\section{Phylome analysis}

The trees reconstructed in the phylome were analyzed using ETE [69] v2.0. Orthology and paralogy relationships between the sequences were established using the species overlap algorithm from ETE v2.0. The algorithm scans the trees from seed to the root and at each node it establishes a duplication or a speciation node depending on the overlap between the species located at each side of the node. If there are common species, the node is assumed to be a duplication node, otherwise it is considered a speciation node. Once duplications were detected, they were mapped onto the species tree. It was assumed that the duplication occurred at the common ancestor of the species derived from the duplication node. The duplication rate at each node was calculated by dividing the duplications mapped at a given node by the number of trees that have an outgroup to the node. Species-specific expansions were also detected by selecting those duplication nodes that only contained sequences from $A$. adeninivorans. Groups of expanded proteins that overlapped in more than $20 \%$ of their sequences were fused into a single-gene expansion.

\section{Detection of horizontally acquired genes}

Gene transfers from prokaryotes to $A$. adeninivorans were detected using a previously published pipeline [36]. Briefly, a BLAST search was performed for each protein encoded in A. adeninivorans against a database that contained 102 completely-sequenced fungi (downloaded from their respective databases), 95 other eukaryotes and 1,395 prokaryotes (downloaded from KEGG as of June 2011). Only genes present in more than 30 prokaryotes, less than 10 fungi and no other eukaryotes were considered to be putative transfers.

\section{Species phylogeny}

The species tree was reconstructed by concatenating 253 genes that were found in all the genomes included in the phylome database and that were exclusively one-to-one orthologs. The genes were concatenated and the tree was reconstructed using RaxML [70]. A second tree was reconstructed using a super-tree approach as implemented in Duptree [71], this algorithm tries to find the species tree that minimizes the number of duplication events that occurred in a set of gene trees. In this case the 4,992 trees reconstructed in the phylome were used.

\section{Microarray design and hybridization for gene expression analyses}

Based on 6,025 annotated chromosomal sequences and 36 putative mitochondrial genes oligos were designed using Agilent Technologies eArray software (design number 035454). Depending on the sequence length of the genes up to ten 60-mers per gene were created resulting in a total of 56,312 A. adeninivorans specific oligos. The microarray was produced by Agilent Technologies (Böblingen, Germany) in $8 \times 60 \mathrm{k}$ format.

Overnight cultures of $A$. adeninivorans LS3 in YMM with nitrate were shifted to YMM containing $4 \mathrm{mM}$ adenine as the sole nitrogen source and YMM with nitrate as a control, respectively. After $2 \mathrm{~h}$ of shaking at $30^{\circ} \mathrm{C}$ and $180 \mathrm{rpm}$ cells were harvested and total RNA was isolated. Probe labeling and microarray hybridization (duplicates) were executed according to the manufacturer's instructions (Agilent Technologies "One-Color Microarray-Based Gene Expression Analysis"; v6.5; Böblingen, Germany).

Analysis of microarray data was performed with the $\mathrm{R}$ package limma [72]. Raw expression values were background corrected (method "normexp") and normalized between arrays (method "quantile"). Differentially expressed genes were detected by fitting a linear model to log2transformed data by an empirical Bayes method [73]. The Bonferroni method was used to correct for multiple testing.

\section{Accession numbers}

A. adeninivorans genome sequence data have been deposited at EMBL under the accession number PRJEB4557 [EMBL:PRJEB4557]. The raw data of 454 reads have been deposited at EMBL/ENA database under the accession number ERP001774 [EMBL: ERP001774].

\section{Additional files}

Additional file 1: Assemblies of 454/Roche data.
Additional file 2: Mitochondrial features of A. adeninivorans.
Additional file 3: Non coding RNAs.
Additional file 4: Centromeres.
Additional file 5: Functional annotation.
Additional file 6: Spliceosomal introns.
Additional file 7: Phylogeny and synteny between A. adeninivorans
and other yeasts.
Additional file 8: Proteins having homologs only in Pezizomycotina
or bacteria.
Additional file 9: Gene families amplified in A. adeninivorans.
Additional file 10: Transporter distribution in hemiascomycete species.
Additional file 11: Tandem gene arrays in A. adeninivorans.
Additional file 12: Mating type locus.
Additional file 13: Homologues of genes involved in mating,
meiosis and sporulation.
Additional file 14: Mating pheromones.
Additional file 15: Tannic acid degradation pathways in
A. adeninivorans.

\section{Abbreviations}

BLAST: Basic Local Alignment Search Tool; bp: base pair; CDS: Coding DNA sequence; CoA: Coenzyme A; EC: Enzyme commission number; GO: Gene 
ontology; kb: kilobase; KEGG: Kyoto encyclopedia of genes and genomes; PCR: Polymerase Chain reaction; PSSM: position-specific scoring matrix; qRT-PCR: Quantitative reverse transcriptase PCR; snRNA: small nuclear ribonucleic acid; snoRNA: Small nucleolar ribonucleic acid; TGA: Tandem gene array; YMM: Yeast minimal medium.

\section{Competing interests}

The authors declare that they have no competing interests.

\section{Authors' contributions}

All authors contributed substantially to the conception or design of the different parts of the work, within the Génolevures consortium or at the IPK. More, their practical contributions were the following: VB, BV, CJ and PW carried out the genome sequencing at CNS-Genoscope, NS designed and supervised the 454 project at the IPK, MC assembled the 454 data and participated to the gap closure, SB mapped the different genome versions, PPG assisted in the visualization of the nuclear genome, PD, TM, DJS, AS, GS developed the annotation tools, J-LS coordinated the genome annotation by the Génolevures consortium, JAC and EW identified the ncRNA, CM analyzed the tRNA content, EB analyzed the rDNA copy number, $\mathrm{PB}, \mathrm{CB}$, SC, LD, CF, PJ, IL, VLL, ML, GM, GFR, CS, JS, M-LS, AT, J-LS, BD, CG, CM and CN curated manually the genome annotation, CN and CG annotated and analyzed the mitochondrial genome, TG and MM-H carried out the phylogenomics studies, TG, MM-H, CG and ET analyzed the protein families, AG and CG analyzed the transporter families, MC and US performed the blast2GO studies, EB and MG analyzed the tannic acid degradation pathway, UH and JR analyzed the n-butanol degradation pathway, AT-S, KB and DJ analyzed the purine degradation pathway, AH mapped the data onto metabolic pathways and created the metabolism figures, MM and SW analyzed the microarray data, RB supervised the biochemical work of the IPK group, US supervised the bioinformatics work of the IPK group, GK designed and supervised the Arxula work of the IPK group, CN, MC, CG, US and GK finalized the manuscript from drafts of all co-authors. All authors read and approved the final manuscript.

\section{Acknowledgements}

The authors would like to thank S. König for 454 sequencing, D. Stengel for 454 data submission to EMBL/ENA, S. Flemming for technical assistance in bioinformatics analysis and software installation, and T. Schmutzer and B. Steuernagel for fruitful discussions about the analysis of the 454 data. This work was supported in part by funding from the Consortium National de Recherche en Génomique (CNRG) to Génoscope, from CNRS (GDR 2354, Génolevures), ANR (ANR-05-BLAN-0331, GENARISE). The computing framework was supported by the funding of the University of Bordeaux 1 , the Aquitaine Région in the program "Génotypage et Génomique Comparée", the ACI IMPBIO "Génolevures En Ligne" and INRIA. We thank the System and Network Administration team in LaBRI for excellent help and advice. J.A.C. is supported by the PhD Program in Computational Biology of the Instituto Gulbenkian de Ciência, Portugal (sponsored by Fundação Calouste Gulbenkian, Siemens SA, and Fundação para a Ciência e Tecnologia; SFRH/BD/33528/2008). M.C. research was supported by a grant of the Deutscher Akademischer Austauschdienst (DAAD). T.G. research was partly supported by a grant from the Spanish Ministry of Economy and Competitiveness (BIO2012-37161). B.D. is a member of Institut Universitaire de France.

\section{Author details}

${ }^{1}$ Leibniz Institute of Plant Genetics and Crop Plant Research (IPK), Corrensstr 3, Gatersleben D-06466, Germany. ${ }^{2}$ AgroParisTech, Micalis UMR 1319, CBAI Thiverval-Grignon F-78850, France. ${ }^{3}$ INRA French National Institute for Agricultural Research, Micalis UMR 1319, CBAI, Thiverval-Grignon F-78850, France. ${ }^{4}$ Institute of Plant Biology and Biotechnology, University of Agriculture in Krakow, Al. 29 Listopada 54, Krakow 31-425, Poland. ${ }^{5}$ LaBRI (UMR 5800 CNRS) and project-team Magnome INRIA Bordeaux Sud-Ouest, Talence F-33405, France. ${ }^{6}$ Bioinformatics and Genomics Programme, Centre for Genomic Regulation (CRG), Dr. Aiguader 88, Barcelona 08003, Spain. ${ }^{7}$ Universitat Pompeu Fabra (UPF), 08003 Barcelona, Spain. ${ }^{8}$ Université de Strasbourg, Architecture et Réactivité de l'ARN, Institut de Biologie Moléculaire et Cellulaire du CNRS, F-67084 Strasbourg, France. ${ }^{9}$ Aix-Marseille Université, CNRS UMR 7283, Laboratoire de Chimie Bactérienne, F-13402 Marseille, Cedex 20, France. ${ }^{10}$ CEA, Saclay Biology and Technologies Institute
(iBiTec-S), Gif-sur-Yvette F-91191, France. "'Université catholique de Louvain, Institut des Sciences de la Vie, Croix du Sud 5/15, Louvain-la-Neuve 1349, Belgium. ${ }^{12} \mathrm{CEA}$, Institut de Génomique, Genoscope, 2 Rue Gaston Crémieux, Évry F-91000, France. ${ }^{13}$ Université Catholique de Louvain, Earth and Life Institute (ELI), Louvain-la-Neuve 1348, Belgium. ${ }^{14}$ School of Biological Sciences, University of Canterbury, Private Bag 4800, Christchurch, New Zealand. ${ }^{15}$ Université de Strasbourg, CNRS UMR7156, Strasbourg F-67000, France. ${ }^{16}$ Institute of Biochemistry, University of Greifswald,

Felix-Hausdorffstraße 4, Greifswald D-17487, Germany. ${ }^{17}$ Institut de Génétique et Microbiologie, Université Paris-Sud, UMR CNRS 8621, F- Orsay CEDEX 91405, France. ${ }^{18}$ Laboratory of Bioinformatics and Protein Engineering, International Institute of Molecular and Cell Biology in Warsaw, ul. Ks. Trojdena 4, Warsaw 02-109, Poland. ${ }^{19}$ CNRS UMR 8030, 2 Rue Gaston Crémieux, Évry F-91000, France. ${ }^{20}$ Université d'Evry, Bd François Mitterand, Evry F-91025, France. ${ }^{21}$ Institut Pasteur, Université Pierre et Marie Curie UFR927, CNRS UMR 3525, F-75724 Paris-CEDEX 15, France. ${ }^{22}$ Université Lyon 1, CNRS UMR 5240, Villeurbanne F-69621, France. ${ }^{23}$ Present address: École Normale Supérieure, Institut de Biologie de l'ENS (IBENS), 46 rue d'Ulm, Paris F-75005, France. ${ }^{24}$ INRA Institut Micalis UMR 1319, AgroParisTech, BIMLip, Avenue de Bretignières, Bât. CBAI, Thiverval-Grignon 78850, France. ${ }^{25}$ Yeast Genetics, Leibniz Institute of Plant Research (IPK), Corrensstrasse 3, Gatersleben 06466, Germany.

Received: 13 November 2013 Accepted: 19 March 2014 Published: 24 April 2014

\section{References}

1. Böer E, Breuer FS, Weniger M, Denter S, Piontek M, Kunze G: Large-scale production of tannase using the yeast Arxula adeninivorans. Appl Microbiol Biotechnol 2011, 92:105-114.

2. Giersberg M, Degelmann A, Bode R, Piontek M, Kunze G: Production of a thermostable alcohol dehydrogenase from Rhodococcus ruber in three different yeast species using the $X$ plor(R)2 transformation/expression platform. J Ind Microbiol Biotechnol 2012, 39:1385-1396.

3. Rauter M, Schwarz M, Becker K, Baronian K, Bode R, Kunze G, Vorbrodt H-M: Synthesis of benzyl $\beta$-d-galactopyranoside by transgalactosylation using a $\beta$-galactosidase produced by the over expression of the Kluyveromyces lactis LAC4 gene in Arxula adeninivorans. J Mol Catal B-Enzym 2013, 97:319-327.

4. Jankowska DA, Trautwein-Schult A, Cordes A, Hoferichter P, Klein C, Bode R, Baronian K, Kunze G: Arxula adeninivorans xanthine oxidoreductase and its application in the production of food with low purine content. J Appl Microbiol 2013, 115:796-807.

5. Hahn T, Tag K, Riedel K, Uhlig S, Baronian K, Gellissen G, Kunze G: A novel estrogen sensor based on recombinant Arxula adeninivorans cells. Biosens Bioelectron 2006, 21:2078-2085.

6. Kaiser C, Uhlig S, Gerlach T, Korner M, Simon K, Kunath K, Florschutz K, Baronian K, Kunze G: Evaluation and validation of a novel Arxula adeninivorans estrogen screen (nAES) assay and its application in analysis of wastewater, seawater, brackish water and urine.Sci Total Environ 2010, 408:6017-6026.

7. Gellissen G, Kunze G, Gaillardin C, Cregg JM, Berardi E, Veenhuis M, van der Klei I: New yeast expression platforms based on methylotrophic Hansenula polymorpha and Pichia pastoris and on dimorphic Arxula adeninivorans and Yarrowia lipolytica - a comparison. FEMS Yeast Res 2005, 5:1079-1096.

8. Wartmann T, Kunze G: Expression of heterologous genes in Arxula adeninivorans budding cells and mycelia. In Non-conventional yeasts in genetics, biochemistry and biotechnology. Edited by Wolf K, Breunig K, Barth G. Berlin-Heidelberg: Springer; 2003:7-13.

9. Haslett ND, Rawson FJ, Barriere F, Kunze G, Pasco N, Gooneratne R, Baronian $\mathrm{KH}$ : Characterisation of yeast microbial fuel cell with the yeast Arxula adeninivorans as the biocatalyst. Biosens Bioelectron 2011. http://dx.doi.org/ 10.1016/j.bios.2011.02.011.

10. Middelhoven WJ, Hoogkamer-Te Niet MV, Kreger-Van Rij NJW: Trichosporon adeninovorans sp. nov., a yeast species utilizing adenine, xanthine, uric acid, putrescine and primary n-alkylamines as the sole source of carbon, nitrogen and energy. Antonie Van Leeuwenhoek 1984, 50:369-378.

11. Gienow U, Kunze G, Schauer F, Bode R, Hofemeister J: The yeast genus Trichosporon spec. LS3;molecular characterization of genomic complexity. Zentralbl Mikrobiol 1990, 145:3-12. 
12. Van der Walt JP, Smith MT, Yamada Y: Arxula gen. nov. (Candidaceae), a new anamorphic, arthroconidial yeast genus. Antonie Van Leeuwenhoek 1990, 57:59-61

13. Middelhoven WJ, de Jong IM, de Winter M: Arxula adeninivorans, a yeast assimilating many nitrogenous and aromatic compounds. Antonie Van Leeuwenhoek 1991, 59:129-137.

14. Kurtzman CP, Robnett CJ: Multigene phylogenetic analysis of the Trichomonascus, Wickerhamiella and Zygoascus yeast clades, and the proposal of Sugiyamaella gen. nov. and 14 new species combinations. FEMS Yeast Res 2007, 7:141-151.

15. Kurtzman CP: Summary of species characteristics. In The Yeasts, a taxonomic study, Volume 2. Edited by Kurtzman CP, Fell JW, Boekhout T. London: Elsevier; 2011:224-227.

16. Curtin CD, Borneman AR, Chambers PJ, Pretorius IS: De-novo assembly and analysis of the heterozygous triploid genome of the wine spoilage yeast Dekkera bruxellensis AWRI1499. PLoS One 2012, 7:e33840.

17. Piskur J, Ling Z, Marcet-Houben M, Ishchuk OP, Aerts A, LaButti K, Copeland A Lindquist E, Barry K, Compagno C, Bisson L, Grigoriev IV, Gabaldón T, Phister T: The genome of wine yeast Dekkera bruxellensis provides a tool to explore its food-related properties. Int J Food Microbio/ 2012, 157:202-209.

18. Morales L, Noel B, Porcel B, Marcet-Houben M, Hullo MF, Sacerdot C, Tekaia F, Leh-Louis V, Despons L, Khanna V, Aury JM, Barbe V, Couloux A, Labadie K, Pelletier E, Souciet JL, Boekhout T, Gabaldon T, Wincker P, Dujon B: Complete DNA sequence of Kuraishia capsulata illustrates novel genomic features among budding yeasts (Saccharomycotina). Genome Biol Evol 2013, 5:2524-2539.

19. Ravin NV, Eldarov MA, Kadnikov W, Beletsky AV, Schneider J, Mardanova ES, Smekalova EM, Zvereva MI, Dontsova OA, Mardanov AV, Skryabin KG: Genome sequence and analysis of methylotrophic yeast Hansenula polymorpha DL1. BMC Genomics 2013, 14:837.

20. Böer E, Steinborn G, Florschütz K, Körner M, Gellissen G, Kunze G: Arxula adeninivorans (Blastobotrys adeninivorans) - A Dimorphic Yeast of Great Biotechnological Potential. In Yeast Biotechnology: Diversity and Applications. Edited by Satyanarayana T, Kunze G. Dordrecht: Springer Science + Business Media B.V; 2009:615-634

21. Kunze G, Kunze I: Characterization of Arxula adeninivorans strains from different habitats. Antonie Van Leeuwenhoek 1994, 65:29-34.

22. Gordon JL, Byrne KP, Wolfe KH: Mechanisms of chromosome number evolution in yeast. PLoS Genet 2011, 7:e1002190.

23. Dujon B: Yeast evolutionary genomics. Nat Rev Genet 2010, 11:512-524

24. Rosel $\mathrm{H}$, Kunze $\mathrm{G}$ : Identification of a group-I intron within the $25 \mathrm{~S}$ rDNA from the yeast Arxula adeninivorans. Yeast 1996, 12:1201-1208.

25. Marck C, Kachouri-Lafond R, Lafontaine I, Westhof E, Dujon B, Grosjean $\mathrm{H}$ : The RNA polymerase III-dependent family of genes in hemiascomycetes: comparative RNomics, decoding strategies, transcription and evolutionary implications. Nucleic Acids Res 2006, 34:1816-1835.

26. Cruz JA, Westhof E: Identification and annotation of noncoding RNAs in Saccharomycotina. C R Biol 2011, 334:671-678.

27. Kovalchuk A, Senam S, Mauersberger S, Barth G: Tyl6, a novel Ty3/gypsylike retrotransposon in the genome of the dimorphic fungus Yarrowia lipolytica. Yeast 2005, 22:979-991.

28. Chalker DL, Sandmeyer SB: Transfer RNA genes are genomic targets for de Novo transposition of the yeast retrotransposon Ty3. Genetics 1990, 126:837-850

29. Ishii $\mathrm{K}$ : Conservation and divergence of centromere specification in yeast. Curr Opin Microbiol 2009, 12:616-622.

30. Souciet JL, Dujon B, Gaillardin C, Johnston M, Baret PV, Cliften P, Sherman DJ, Weissenbach J, Westhof E, Wincker P, Jubin C, Poulain J, Barbe V, Ségurens B, Artiguenave F, Anthouard V, Vacherie B, Val ME, Fulton RS, Minx P, Wilson R, Durrens P, Jean G, Marck C, Martin T, Nikolski M, Rolland T, Seret ML, Casarégola S, Despons L, et al: Comparative genomics of protoploid Saccharomycetaceae. Genome Res 2009, 19:1696-1709.

31. Neuvéglise C, Marck C, Gaillardin C: The intronome of budding yeasts. C R Biol 2011, 334:679-686.

32. Böer E, Bode R, Mock HP, Piontek M, Kunze G: Atan1p-an extracellular tannase from the dimorphic yeast Arxula adeninivorans: molecular cloning of the ATAN1 gene and characterization of the recombinant enzyme. Yeast 2009, 26:323-337.

33. Böer E, Mock HP, Bode R, Gellissen G, Kunze G: An extracellular lipase from the dimorphic yeast Arxula adeninivorans: molecular cloning of the
ALIP1 gene and characterization of the purified recombinant enzyme. Yeast 2005, 22:523-535.

34. Gabaldon T: Large-scale assignment of orthology: back to phylogenetics? Genome Biol 2008, 9:235.

35. Huerta-Cepas J, Capella-Gutierrez S, Pryszcz LP, Denisov I, Kormes D, MarcetHouben M, Gabaldon T: PhylomeDB v3.0: an expanding repository of genome-wide collections of trees, alignments and phylogeny-based orthology and paralogy predictions. Nucleic Acids Res 2011, 39:D556-D560.

36. Marcet-Houben M, Gabaldon T: Acquisition of prokaryotic genes by fungal genomes. Trends Genet 2010, 26:5-8.

37. Rolland T, Neuveglise C, Sacerdot C, Dujon B: Insertion of horizontally transferred genes within conserved syntenic regions of yeast genomes. PLoS One 2009, 4:e6515.

38. Huerta-Cepas J, Gabaldon T: Assigning duplication events to relative temporal scales in genome-wide studies. Bioinformatics 2011, 27:38-45.

39. Edgar RC: MUSCLE: a multiple sequence alignment method with reduced time and space complexity. BMC Bioinforma 2004, 5:113.

40. Butler G, Rasmussen MD, Lin MF, Santos MA, Sakthikumar S, Munro CA, Rheinbay E, Grabherr M, Forche A, Reedy JL, Agrafioti I, Arnaud MB, Bates S, Brown AJ, Brunke S, Costanzo MC, Fitzpatrick DA, de Groot PW, Harris D, Hoyer LL, Hube B, Klis FM, Kodira C, Lennard N, Logue ME, Martin R, Neiman AM, Nikolaou E, Quail MA, Quinn J, et al: Evolution of pathogenicity and sexual reproduction in eight Candida genomes. Nature 2009, 459:657-662.

41. Middelhoven WJ: Catabolism of benzene compounds by ascomycetous and basidiomycetous yeasts and yeastlike fungi. A literature review and an experimental approach. Antonie Van Leeuwenhoek 1993, 63:125-144.

42. Middelhoven WJ, Coenen A, Kraakman B, Sollewijn Gelpke MD: Degradation of some phenols and hydroxybenzoates by the imperfect ascomycetous yeasts Candida parapsilosis and Arxula adeninivorans: evidence for an operative gentisate pathway. Antonie Van Leeuwenhoek 1992, 62:181-187.

43. Werner AK, Witte CP: The biochemistry of nitrogen mobilization: purine ring catabolism. Trends Plant Sci 2011, 16:381-387.

44. Jankowska DA, Faulwasser K, Trautwein-Schult A, Cordes A, Hoferichter P, Klein C, Bode R, Baronian K, Kunze G: Arxula adeninivorans recombinant adenine deaminase and its application in the production of food with low purine content. J App/ Microbiol 2013, 115:1134-1146.

45. Perez MD, Gonzalez C, Avila J, Brito N, Siverio JM: The YNT1 gene encoding the nitrate transporter in the yeast Hansenula polymorpha is clustered with genes YNI1 and YNR1 encoding nitrite reductase and nitrate reductase, and its disruption causes inability to grow in nitrate. Biochem J 1997, 321:397-403.

46. Böer E, Schroter A, Bode R, Piontek M, Kunze G: Characterization and expression analysis of a gene cluster for nitrate assimilation from the yeast Arxula adeninivorans. Yeast 2009, 26:83-93.

47. Gournas C, Oestreicher N, Amillis S, Diallinas G, Scazzocchio C: Completing the purine utilisation pathway of Aspergillus nidulans. Fungal Genet Biol 2011, 48:840-848.

48. Field J, Leyendeckers MJ, Sierra-Alvarez R, Lettinga G, Habets L: Continuous anaerobic treatment of autoxidized bark extracts in laboratory-scale columns. Biotechnol Bioeng 1991, 37:247-255.

49. Aguilar CN, Rodriguez R, Gutierrez-Sanchez G, Augur C, Favela-Torres E, PradoBarragan LA, Ramirez-Coronel A, Contreras-Esquivel JC: Microbial tannases: advances and perspectives. Appl Microbiol Biotechnol 2007, 76:47-59.

50. Bhat TK, Singh B, Sharma OP: Microbial degradation of tannins-a current perspective. Biodegradation 1998, 9:343-357.

51. Lekha PK, Lonsane BK: Production and application of tannin acy hydrolase: state of the art. Adv Appl Microbiol 1997, 44:215-260.

52. Sietmann R, Uebe R, Boer E, Bode R, Kunze G, Schauer F: Novel metabolic routes during the oxidation of hydroxylated aromatic acids by the yeast Arxula adeninivorans. J Appl Microbiol 2010, 108:789-799.

53. Li H, Durbin R: Fast and accurate short read alignment with BurrowsWheeler transform. Bioinformatics 2009, 25:1754-1760.

54. Li H, Handsaker B, Wysoker A, Fennell T, Ruan J, Homer N, Marth G, Abecasis G, Durbin R: The sequence Alignment/Map format and SAMtools. Bioinformatics 2009, 25:2078-2079.

55. Kurtz S, Phillippy A, Delcher AL, Smoot M, Shumway M, Antonescu C, Salzberg SL: Versatile and open software for comparing large genomes. Genome Biol 2004, 5:R12.

56. Louis VL, Despons L, Friedrich A, Martin T, Durrens P, Casaregola S, Neuveglise C, Fairhead C, Marck C, Cruz JA, Straub ML, Kugler V, Sacerdot C, 
Uzunov Z, Thierry A, Weiss S, Bleykasten C, De Montigny J, Jacques N, Jung P, Lemaire M, Mallet S, Morel G, Richard GF, Sarkar A, Savel G, Schacherer J, Seret ML, Talla E, Samson G, et al: Pichia sorbitophila, an interspecies yeast hybrid, reveals early steps of genome resolution after polyploidization. G3 (Bethesda) 2012, 2:299-311.

57. Sherman DJ, Martin T, Nikolski M, Cayla C, Souciet UL, Durrens P. Genolevures: protein families and synteny among complete hemiascomycetous yeast proteomes and genomes. Nucleic Acids Res 2009, 37:D550-D554

58. Krzywinski M, Schein J, Birol I, Connors J, Gascoyne R, Horsman D, Jones SJ, Marra MA: Circos: an information aesthetic for comparative genomics. Genome Res 2009, 19:1639-1645.

59. Bendtsen JD, Nielsen $H$, von Heijne G, Brunak S: Improved prediction of signal peptides: SignalP 3.0. J Mol Biol 2004, 340:783-795.

60. Li L, Stoeckert CJ Jr, Roos DS: OrthoMCL: identification of ortholog groups for eukaryotic genomes. Genome Res 2003, 13:2178-2189.

61. Landan G, Graur D: Heads or tails: a simple reliability check for multiple sequence alignments. Mol Biol Evol 2007, 24:1380-1383.

62. Katoh $\mathrm{K}$, Kuma $\mathrm{K}$, Toh $\mathrm{H}$, Miyata T: MAFFT version 5: improvement in accuracy of multiple sequence alignment. Nucleic Acids Res 2005, 33:511-518

63. Subramanian AR, Kaufmann M, Morgenstern B: DIALIGN-TX: greedy and progressive approaches for segment-based multiple sequence alignment. Algorithms Mol Biol 2008, 3:6.

64. Wallace IM, O'Sullivan O, Higgins DG, Notredame C: M-Coffee: combining multiple sequence alignment methods with T-Coffee. Nucleic Acids Res 2006, 34:1692-1699.

65. Capella-Gutierrez S, Silla-Martinez JM, Gabaldon T: trimAl: a tool for automated alignment trimming in large-scale phylogenetic analyses. Bioinformatics 2009, 25:1972-1973.

66. Gascuel O: BIONJ: an improved version of the $\mathrm{NJ}$ algorithm based on a simple model of sequence data. Mol Biol Evol 1997, 14:685-695.

67. Akaike H: Data analysis by statistical models. No To Hattatsu 1992, 24:127-133,

68. Guindon S, Dufayard JF, Lefort V, Anisimova M, Hordijk W, Gascuel O: New algorithms and methods to estimate maximum-likelihood phylogenies: assessing the performance of PhyML 3.0. Syst Biol 2010, 59:307-321.

69. Huerta-Cepas J, Dopazo J, Gabaldon T: ETE: a python environment for tree exploration. BMC Bioinforma 2010, 11:24

70. Stamatakis A, Aberer AJ, Goll C, Smith SA, Berger SA, Izquierdo-Carrasco F: RAxML-light: a tool for computing TeraByte phylogenies. Bioinformatics 2012. doi:10.1093/bioinformatics/bts309.

71. Wehe A, Bansal MS, Burleigh JG, Eulenstein O: DupTree: a program for large-scale phylogenetic analyses using gene tree parsimony Bioinformatics 2008, 24:1540-1541.

72. Smyth GK: Limma: linear models for microarray data. In Bioinformatics and computational biology solutions using $R$ and Bioconductor. Edited by Gentleman R, Carey V, Dudoit SI, Irizarry R, Huber W. New York: Springer; 2005:397-420

73. Smyth GK: Linear models and empirical bayes methods for assessing differential expression in microarray experiments. Stat Appl Genet Mol Biol 2004. doi:10.2202/1544-6115.1027.

doi:10.1186/1754-6834-7-66

Cite this article as: Kunze et al:: The complete genome of Blastobotrys (Arxula) adeninivorans LS3 - a yeast of biotechnological interest. Biotechnology for Biofuels 2014 7:66.

\section{Submit your next manuscript to BioMed Central and take full advantage of:}

- Convenient online submission

- Thorough peer review

- No space constraints or color figure charges

- Immediate publication on acceptance

- Inclusion in PubMed, CAS, Scopus and Google Scholar

- Research which is freely available for redistribution

Submit your manuscript at www.biomedcentral.com/submit
C Biomed Central 